\title{
RECEIVER TEMPERATURE MAPS OF PARABOLIC COLLECTOR USED FOR SOLAR FOOD COOKING APPLICATION IN ALGERIA
}

\author{
F. Yettou ${ }^{1, *}$, A. Gama ${ }^{1}$, N.L. Panwar ${ }^{2}$, B. Azoui ${ }^{3}$, A. Malek ${ }^{4}$
}

\begin{abstract}
Limited fossil resources and environmental problems imply that development of solar thermal appliances will play major role in incoming years, especially to meeting domestic energy requirements. The cooking energy demand, which is the largest primary energy-consuming sector and, are continuously increasing. This research paper deal with the temperatures and efficiency mapping of a realized parabolic solar cooker tested in Saharan region of Ghardaîa (Algeria) climatic conditions. Using Black body temperature equation's based on Stefan-Boltzmann law, maps for focal areas receiver temperatures of the cooker are obtained by converting obtained results from optical simulation to thermal values. Several maps are generated through present study for both summer and winter with clear and cloud skies. It was found that cooker temperature values obtained during experimentations and that estimated using the proposed approach has good agreement. The rate of using the cooker from Northern to Southern regions of the country was not identical. For cloudy skies, the major area of the country is favorable for the use of the cooker during winter months. For clear skies, the mapping results indicate that the realized cooker is efficient in all the country throughout the summer season with temperatures exceeding $110^{\circ} \mathrm{C}$. The use of the cooker will be reduced by going in South to North regions during the winter months, depending on the amount of solar radiations received.
\end{abstract}

\section{Keywords: Solar Radiation, Parabolic Solar Cooker, Temperature Maps, Food Cooking}

\section{INTRODUCTION}

When considering thermal applications of solar energy, solar cooking is the best option and the most promising appliance using solar energy. The use of solar cookers provides many advantages like fuel economy, greenhouse gases mitigation, firewood saving, lower cost and high durability [1]. However, in many parts of the world especially in developing countries, wood and fossil fuel-based cooking still predominate with the highest share in the global energy consumption of the residential sector. This situation poses some serious ecological problems such as deforestation [2], economical and health problems are also among the consequences of firewood use.

Algeria lies in the sunny belt of the world (Figure 1). The insulation time over the quasi-totality of the national territory exceeds $2000 \mathrm{~h}$ annually and can reach $3900 \mathrm{~h}$ in the high plains and Sahara. The daily solar energy obtained on a horizontal surface is $5 \mathrm{kWh} / \mathrm{m}^{2}$ over the major part of the national territory, or about 1700 $\mathrm{kWh} / \mathrm{m}^{2} /$ year for the North and $2263 \mathrm{kWh} / \mathrm{m}^{2} /$ year for the South of the country [3]. These are very favorable climatic conditions for all solar energy applications, especially for residential cooking, when considers that the global Algerian demand for cooking energy is expected to increase greatly with the increasing population over the incoming years and that actual demand is met through using of natural gas (cities) and by forest wood in rural and isolated areas.

Solar cookers are becoming very popular in many countries; many different designs are developed all over the world. However, there is a need to evaluate solar cookers and compare different designs calls for testing procedures and performance parameters which represent their respective thermal performance [4]. Mullick; Kandpal and Saxena [5] proposed two figures of merits in order to evaluate the thermal performance of a box type solar cooker. In addition, a test method of solar cookers has also been suggested by Funk [6, 7]; in which the performance is given by two parameters, namely, adjusted cooking power and overall heat loss coefficient was also adapted. On the other hand, each design needs to be suited to specific climate conditions. This development

This paper was recommended for publication in revised form by Regional Editor Jaap Hoffman Hoffman

${ }^{1}$ Unité de Recherche Appliquée en Energies Renouvelables, CDER, 47133, Ghardaïa, Algeria

${ }^{2}$ Department of Renewable Energy Engineering, Maharana Pratap University of Agriculture and Technology, India

${ }^{3}$ Laboratoire de Recherche LEB, Département d'Electrotechnique, Université Hadj Lakhdar, Boukhlouf Med ElHadi, Batna, Algeria

${ }^{4}$ Centre de Développement des Energies Renouvelables, CDER, 16340 Algiers, Algeria

${ }^{\star}$ E-mail address: yettou.t@gmail.com

Manuscript Received 16 June 2016, Accepted 22 November 2016 
requires a good fundamental understanding of the relationship between key design variables and performance [7]. The energy efficiency of a solar cooker, conventionally is used to measure solar cooker efficiency. The energy efficiency is inadequate as a measure of efficiency because it does not take into account all the considerations necessary in solar cooker evaluation. Exergy analysis provides an alternative means of evaluating and comparing solar cookers [8-10]. Exergy efficiency accounts for the temperatures associated with energy transfers to and from the solar cooker, as well as the quantities of energy transferred, and consequently provide a measure of how nearly the solar cooker approaches ideal efficiency [11].

The amount of power produced by solar cookers depends on the amount of sunlight to which it is exposed. As the sun's position changes throughout the day, the solar systems must be adjusted several times during cooking. For this purpose, booster mirrors are usually added to box-type solar cookers (BSCs), single or two axis tracking systems are used by parabolic solar cookers (PSCs). Both for two type cookers, the tracking is difficult especially, when the cooker is loaded (case of BSCs) and when the manual device is used to rotate the assembly (case of PSCs). The performance of solar cookers can be optimized when the cookers are orientated in such a way that the incident sun lights fall onto solar cookers with an incident angle equal to zero and therefore the total losses in the absorber/focal point are the least, so that to reduce the high accuracy requirement for tracking and to overcome the need of standing in the sun, which are the main drawbacks of most solar cookers [12].

As underlined by Panwar; Kaushik and Kothari [13], that over the period from 1971 to $1995, \mathrm{CO}_{2}$ emissions grew at an average rate of $1.7 \%$ per year [14]. By 2020, the developing countries could account for half of global $\mathrm{CO}_{2}$ emissions. Solar cooking technology may be one of the attractive options in developing countries capable to meet energy cooking demand with minimizing the $\mathrm{CO}_{2}$ emission all over the world. Nandwani [15] conducted a study on the ecological benefits of solar cookers in Costa Rica. According to his results, 16.8 million tons of firewood can be saved and the emission of 38.4 million tons of $\mathrm{CO}_{2}$ per year can also be prevented. Hernandez and Huelsz [16] presented the optimization of optogeometrical design of a solar oven for the intertropical zone. It was found that the constructed oven can save a potential quantity of wood of $850 \mathrm{~kg}$ per year. Nahar has conducted some studies for several years [17-19] on different designs of solar cookers in Indian climatic conditions and $\mathrm{CO}_{2}$ emission potential. It was estimated that for different cookers, the saved energy was estimated maximum of $5175 \mathrm{MJ}$ of energy per year.

In our recent work [20,21], the absorber temperature maps of a box-type solar cooker with inclined aperture area were established. In this work, the authors attempted to evaluate the thermal efficiency of a paraboloidal concentrator solar cooker in Algerian climatic conditions using a new approach based on optical simulation of concentrated solar radiation. The estimated temperature maps of the concentrator receiver were generated by this study for all Algerian cities and for several cases. In order to validate the results of simulation experimentally, the parabolic solar cooker was designed and realized by the authors at Applied Research Unit on Renewable Energies of Ghardaîa (Algeria) for domestic cooking applications.

\section{SOLAR COOKERS: DEFINITION AND TYPES}

Solar cookers absorb solar energy and convert it to heat, which is utilized to cook food. Solar cookers also enable some significant processes, such as pasteurization and sterilization [22]. Several types of solar cookers have been developed and are still being modified by researchers and scientists worldwide. The available solar cookers can be classified into three main categories box type, concentrating type and indirect type. However, more recent classification of solar cooker was proposed by Yettou; Azoui; Malek; Gama and Panwar [12].

\section{Box solar cookers}

A box solar cooker (BSC) consists of an insulated box with a transparent glass cover and a plate absorber painted black in order to absorb a maximum amount of sunlight [22,23]. The box is usually equipped with a mirror booster to reflect solar radiation into the box. A maximum of four cooking vessels can be placed inside the box cooker $[24,25]$. Using the box type, a temperature around $100{ }^{\circ} \mathrm{C}$ is achieved; this temperature is suitable for cooking by boiling [26]. Box-type solar cookers are slow to heat up but work satisfactorily under conditions in which there is diffuse radiation, convection heat loss caused by wind, intermittent cloud cover and low ambient temperature [7, 27].

Many scientists and manufacturers over the world are interested by box solar cookers [28-32]. In recent years, researchers highly focused on developing novel designs of solar cookers. 

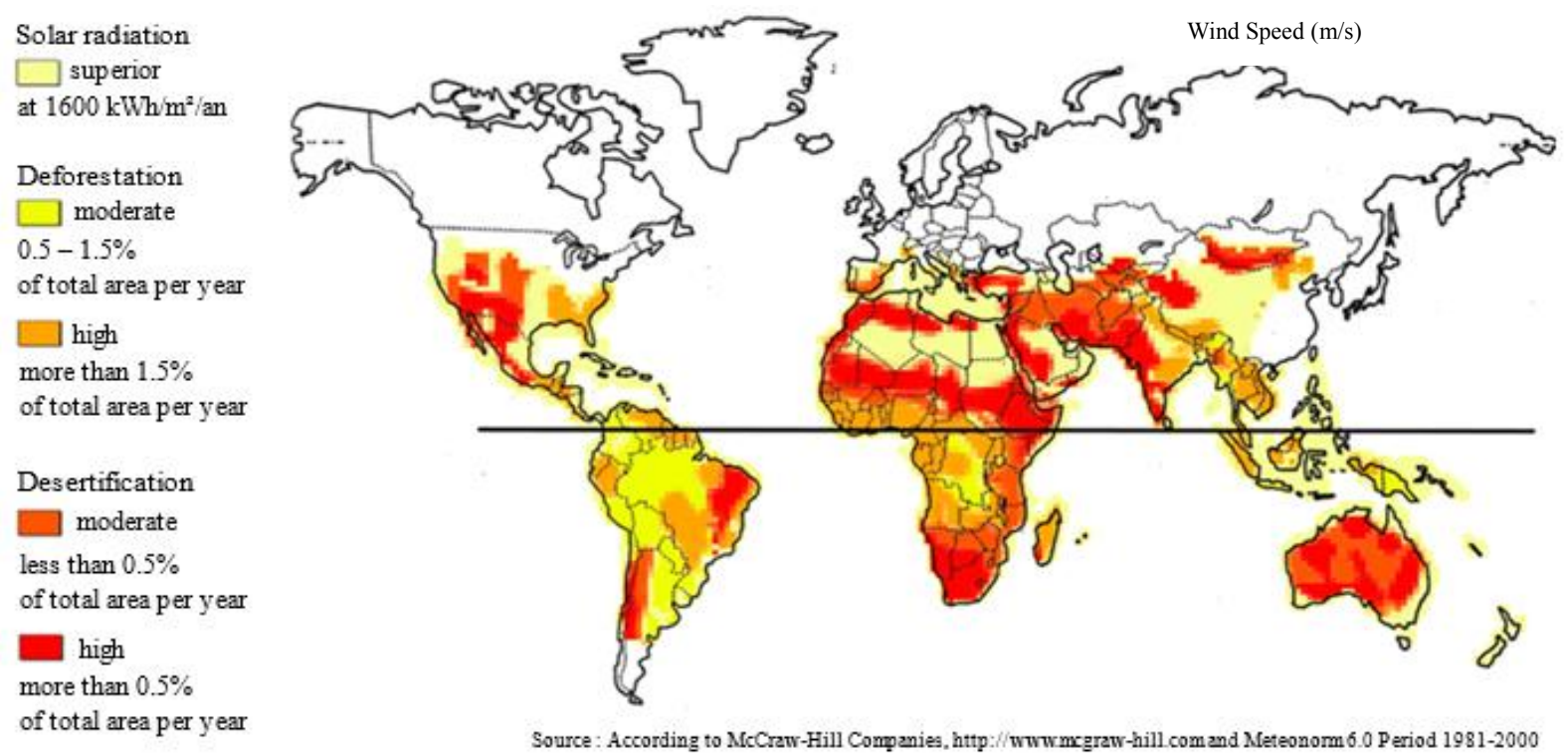

Source : According to MeCraw-Hill Companies, http:/wwwmgraw-hill comend Meteonorm6.0 Period 1981-2000

Figure 1. Priority areas of the world for the development of solar cooking.

In 2012, Mahavar; Sengar; Rajawat; Verma and Dashora [33] presented the design development and, thermal and cooking performance studies of a novel Single Family Solar Cooker (SFSC). In early 2013, they fabricated a Solar Rice Cooker (SRC) [34]. Kumar; Agravat; Chavda and Mistry [35] fabricated and tested a multipurpose domestic solar cooker cum dryer based on truncated pyramid geometry, at the Sardar Patel Renewable Energy Research Institute of India. They also designed and constructed a truncated pyramid geometry based multipurpose solar device, which could be used for domestic cooking as well as water heating [36]. In early 2013, Farooqui [37] presented an innovative work, which consists of a novel mechanism for one-dimensional tracking of box type solar cookers. More recently, Gama; Azoui; Malek; Panwar and Gama [38] presented the energy and exergy evaluation of solar box cooker under climatic conditions of Algeria.

\section{Concentrating solar cookers}

Concentrating-type cookers utilize multifaceted mirrors, Fresnel lenses, or parabolic concentrtors to attain higher temperatures (up to $200{ }^{\circ} \mathrm{C}$ ) [26]. The most popular is the parabolic solar cooker, which consists of a parabolic reflector supported by a stand with a cooking pot placed at the focus point of the cooker. Concentratingtype cookers are suitable for frying and food cooking but need frequent adjustment to track the sun's position. Therefore, theses cookers are usually equipped with sun following devices. The most recent work done in this field is the sun tracking system with absorber displacement of Gama; Larbes; Malek; Yettou and Adouane [39].

Concentrating-type cookers have attracted more attention and several concepts are being brought into reality around the world [40-42]. Recently, more advanced concentrating type designs have been developed, such as the parabolic solar cooker constructed by Al-Soud; Abdallah; Akayleh; Abdallah and Hrayshat [43], the spherical type solar cooker with automatic two-axis sun tracking system realized by Abu-Malouh; Abdallah and Muslih [44], and the solar cooking stove, which uses a Fresnel lens for concentration of sunlight, designed and tested in 2011 by Valmiki; Li; Heyer; Morgan; Albinali; Alhamidi and Wagoner [45]. A solar coffee maker was also realized and operated by Sosa-Montemayor; Jaramillo and del Río [46], a solar fryer designed and developed by Gallagher [47], a solar cooker and water heater was designed and built in 2010 by Badran; Badran; Yousef; Joudeh; Hamad; Halawa and Hassouneh [48], and mostly recently, a new portable solar cooker with PCM based heat storage created by Lecuona; Nogueira; Ventas; Rodríguez-Hidalgo and Legrand [49].

\section{Indirect solar cookers}

The indirect-type solar cookers use a heat-transfer fluid to carry thermal energy from the point of collection to the cooking vessel(s) [26]. This mode of energy collection is useful for indoor cooking applications. One of such types is the cooker realized by Mehmet Esen [50] which uses a vacuum-tube collector with heat pipes 
containing different refrigerants, and the cooker employing flat-plate collectors with the possibility of indoor cooking experimented with by Hussein; El-Ghetany and Nada [51].

\section{DESCRIPTION OF THE PARABOLIC SOLAR COOKER}

The realized parabolic solar cooker (PSC) consists of a parabolic reflector supported by a stand with a cooking pot placed at the focus point of the cooker. The shape of the cooker is paraboloidal type having $0.9 \mathrm{~m}$ aperture diameter (Figure 2). This solar cooker has a steel structure and uses small mirror facets as the reflector. The reflective area of the solar cooker is $0.72 \mathrm{~m}^{2}$. The focal length of the cooker is $0.5 \mathrm{~m}$ while the focal area of the cooker is $0.10 \mathrm{~m}^{2}$. The concentration ratio of this cooker is calculated about 24 . The reflectivity of the mirror facets is 0.80 . The Aluminum cooking pot $(20 \mathrm{~cm}$ in diameter and $10 \mathrm{~cm}$ in height) filled with water and equipped with a black cover was placed at the focus area of the cooker. Parabolic reflector was assigned a reflectivity of $100 \%$ and its receiver is considered as perfect absorber. The solar tracking in this cooker is done manually, the cook has to reposition it each 8-10 min. In recent study [52], it was explained a new method based on optical losses to determine the time adjustment for PSC. According to the results, a time adjustment of 8 minutes is required for our parabolic solar cooker.



Figure 2. Schematic of a parabolic solar cooker with tracking system.

\section{METHODOLOGY}

In order to draw different cooker maps, several steps are necessary (Figure 3):

Modeling normal beam solar irradiances for clear and cloud skies based on sun position parameters, data for Linke turbidity and sunshine fraction factors using Matlab language [53, 54].

By importing the conception design of parabolic solar cooker from Solid Works software [55], a simulation of concentrated solar irradiance on a concentrator receiver was done for the 48 cities of Algeria by inserting modeling results as inputs in to TracePro software [56].

Solar cookers are a direct application of the laws of heat transfer by radiation (Sephan-Boltzmann law), which states that the flux density emitted or received by a body is proportional to the 4 th power of its temperature. Thus, the next step is the conversion of obtained optical results for concentrated irradiance to thermal values using Stephan -Boltzmann law as follow [57]:

$$
C_{\max } R_{1} R_{2} I_{S}=\sigma_{s} T^{4}
$$

Where: $\mathrm{C}_{\max }$ is the concentration ratio, it is equal to the concentrated radiation / incident radiation, $\mathrm{R}_{1} \mathrm{R}_{2}$ $=\mathrm{R}$ is the reflectivity of the glasses, $\mathrm{I}_{\mathrm{s}}$ is the incident solar radiation in $\mathrm{W} / \mathrm{m}^{2}, \sigma_{\mathrm{s}}$ is the Stefan-Boltzmann constant $\left(5.67 \times 10^{-8} \mathrm{~W} / \mathrm{m}^{2} \mathrm{~K} 4\right), \mathrm{T}^{4}$ is the temperature in ${ }^{\circ} \mathrm{K}$.

The above steps are applied to 62 points (including the 48 cities) for several geographical locations of Algeria to create a compatible matrix format for Surfer Golden Software [58]. The Golden Software Surfer Inc is a universal tool path contours, surfaces and 3D cartographic representations. It also allows to interpolate between two adjacent points with high accuracy. Reading the matrix file XYZ by the Surfer software, offers the possibility to project the obtained results on illustrative and analyzable maps. So, maps of solar irradiance, concentrated solar radiation and temperatures are obtained. 



Figure 3. Steps to obtain parabolic solar cooker maps based on optical approach.

\section{OPTICAL SIMULATION, EXPERIMENTAL WORK AND VALIDATION}

For each city (Lat, Long, Alt) of Algeria, an optical simulation of concentrated solar irradiance on a concentrator receiver was done. Figures 4.a, 4.b, 4.c and 4.d represents the results of simulation, by TracePro software; of concentrated irradiance on the focus area for clear and cloudy days in December and June months, respectively.

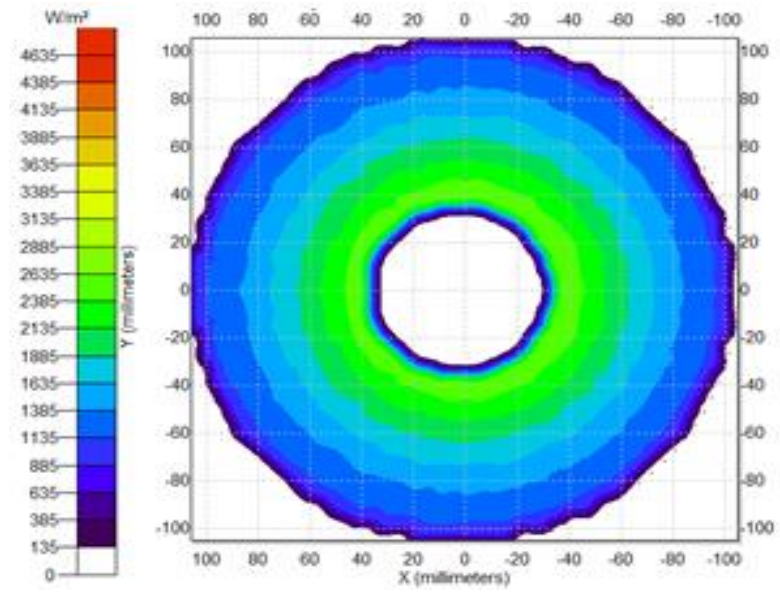

(a) PSC in clear day (December month)



(c) PSC in clear day (June month)


(b) PSC in cloudy day (December month)


(d) PSC in cloudy day (June month)

Figure 4. Results of the simulation for the concentrated irradiance on the focal area of the PSC in Ghardaîa site's. 
By applying the Stefan-Boltzmann formula for thermal conversion of optical values, the following results were obtained for pot water temperatures in December month at Ghardaîa city: $92.6{ }^{\circ} \mathrm{C}$ for clear sky and $84.3{ }^{\circ} \mathrm{C}$ for cloud sky. By comparing the theoretical results with experimental data measured at Ghardaîa (Figure 5), it was found that the values are in good agreement with an acceptable average error of $\pm 3{ }^{\circ} \mathrm{C}$. Under direct sun exposition, the cooker water temperatures achieved $95^{\circ} \mathrm{C}$ for clear sky and $82{ }^{\circ} \mathrm{C}$ for overcast sky conditions, just after noon; when the ambient temperature was $19^{\circ} \mathrm{C}$ and $17^{\circ} \mathrm{C}$, respectively.



Figure 5. Practical results of the temperature profil for the PSC's focal area with solar radiation, measured on the Ghardaîa site for the test carried on December month.

\section{MAPPING RESULTS}

To generate desired maps (direct normal radiation, concentrated radiation, temperature receivers), above said approach were applied, namely; mathematical modeling, optical simulation, data conversion, for the entire Algerian territory. For this, and in order to cover all most of the country's area; 62 point including 48 cities with different geographic coordinates (Lat, Lon, Alt) original of Google Earth Service was selected.

\section{Solar radiation and concentrated radiation maps}

The web-based solar radiation resource SoDa (www.soda-is.com/) [59] can be used to calculate monthly values of $\mathrm{TL}_{2}$ for any location in the world by entering geographical coordinates and elevation data [60]. For present studies, a data base for each combination (Lat, Lon, Alt) of Algeria with step of $280 \mathrm{~km}$ was created [61].

To assess the normal beam irradiances for overcast conditions, a sunshine fraction factor $\sigma_{\mathrm{o}}$ was used. A sunshine fraction data for Algerian cities is available on Capderou book's [62].

Figures 6.a and 6.b show the map of mean values of Linke turbidity factor used for calculating direct normal irradiance on the parabolic receiver, for clear sky on winter and summer season, respectively. Mapping on Figures 7.a and 7.b represent the instantaneous incident irradiances for December and June month obtained from our Matlab program. Figures 8.a and 8.b reveals the sunshine fraction for all Algerian cities used for estimating the solar irradiance incident on the cooker receiver on cloudy skies.

Figures 9.a, 9.b, 10.a and 10.b represent the mapping of obtained results for concentrated irradiances on the receiver for clear skies on winter and summer months and for cloudy skies on winter and summer months, respectively.

It can easily notice, from these cards; the important quantity of concentrated solar radiation incident on the cooker receiver on summer season compared to winter. This remark is also valuable for cloudy days, especially in the south of the country. The amount of average concentrated irradiance at the receiver of the cooker is estimated as $2676 \mathrm{~W} / \mathrm{m}^{2}$ for a typical day of June month at noon (Figure $10 . \mathrm{b}$ ) and as $1393 \mathrm{~W} / \mathrm{m}^{2}$ for typical day of December month (Figure 10.a). 




(a)



(b)

Figure 6. Mapping of Linke turbidity factor mean values for: (a) December month (b) June month in Algeria.



(a)



(b)

Figure 7. Mapping of normal beam solar irradiances for: (a) December month, (b) June month in Algeria.



(a)

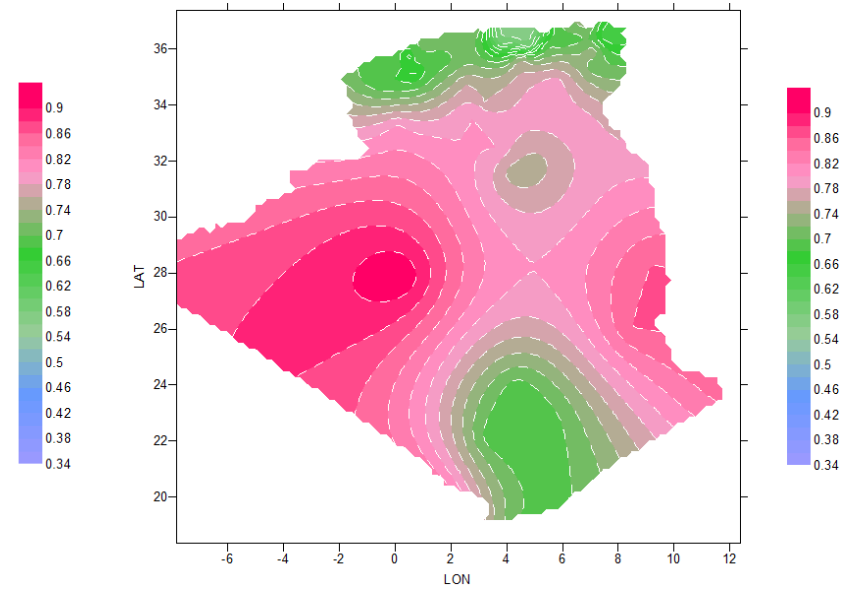

(b)

Figure 8. Mapping of sunshine fraction mean values for: (a) December month, (b) June month in Algeria. 
These quantities are significantly increased for clear skies with $4104 \mathrm{~W} / \mathrm{m}^{2}$ average value in summer (Figure 9.b) and $2240 \mathrm{~W} / \mathrm{m}^{2}$ in winter (Figure 9.a), this is mainly due to the significant amount of direct normal solar radiation received throughout the Algerian territory during the year. The average value of direct normal irradiance in June month at noon is estimated at $877 \mathrm{~W} / \mathrm{m}^{2}$ (Figure 7.b), an average value in the month of December is estimated as $867 \mathrm{~W} / \mathrm{m}^{2}$ (Figure 7.a).



(a)



(b)

Figure 9. Obtained map for concentrated solar irradiance on PSC's receiver for: (a) typical winter season clear days, (b) typical summer season clear days.



(a)



(b)

Figure 10. Obtained map for concentrated solar irradiance on PSC's receiver for: (a) typical winter season cloud days, (b) typical summer season cloud days.

\section{Cooker receiver temperature maps}

Figures 11.a and 11.b shows the mapping of temperatures attained by the cooker receiver obtained for winter and summer months under clear sky for Algeria, respectively.

According to the iso-temperature map distributions, it is clear that the solar cooker can be used in all Algerian territory in clear sky summer season (Figure 11.b) with temperatures exceeding $110{ }^{\circ} \mathrm{C}$. For the winter season, the use duration of the cooker is reduced by going from South to North cities (Figure 11.a), depending on the amount of solar radiations. The recorded temperatures are between $62.7^{\circ} \mathrm{C}$ and $68.4{ }^{\circ} \mathrm{C}$ for sites with latitude greater than $36^{\circ} \mathrm{N}$ and between $70.2^{\circ} \mathrm{C}$ and $86.2^{\circ} \mathrm{C}$ for site's latitude $34^{\circ}<\varphi<36^{\circ} \mathrm{N}$, the estimated temperatures are above $93{ }^{\circ} \mathrm{C}$ for South of the country. 




(a)



(b)

Figure 11. Receiver temperature maps of parabolic solar cooker for Algeria clear sky as obtained by the proposed approach for: (a) typical winter season, (b) typical summer season.

The receiver temperatures for winter and summer months under overcast conditions in the Figures 12.a and $12 . \mathrm{b}$ are also presented.

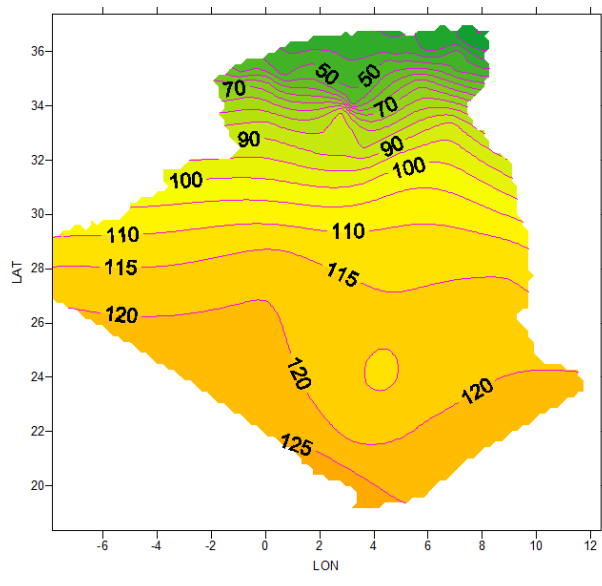

(a)



(b)

Figure 12. Receiver temperature maps of parabolic solar cooker for Algeria cloud sky as obtained by the proposed approach for: (a) typical winter season, (b) typical summer season.

The use of the solar cooker under overcast conditions became inefficient in North and height plains regions (Figure 12.a) due to low temperatures (below $80^{\circ} \mathrm{C}$ ). However, the cooker is exploitable on the most area of the country during summer season almost under cloud sky; temperatures are estimated between $81.3^{\circ} \mathrm{C}$ and $90.7^{\circ} \mathrm{C}$ in the North and between $94.6{ }^{\circ} \mathrm{C}$ and $167.7^{\circ} \mathrm{C}$ in the South (Figure 12.b).

\section{CONCLUSION}

A new approach was employed to generate temperature maps of a solar receiver for a domestic parabolic concentrator used for cooking purposes. A model was developed to calculate solar irradiance for 48 different cities of Algeria's; an optical simulation of concentrated solar radiation was applied to each location. The simulation results are converted to temperature values based on Stefan-Boltzmann law. The hourly temperature maps produced can predict the cooker efficiency under Algerian climatic conditions for clear and cloudy skies. Nevertheless, solar cooking remains a reality that allows healthy cooking food with energy savings and respect for the environment.

\section{ACKNOWLEDGMENTS}

The Small Thermodynamics Power Plants group (MCTH) from URAER, Ghardaïa would like to express their sincere gratitude to Dr. Narayan Lal Panwar from Maharana Pratap University of Agriculture and Technology 
(Rajasthan, India) for his support, valuable suggestions and critical feedback. Authors are very thankful to Renewables Energies Development Center (CDER, Algeria) and Applied Research Unit on Renewable Energies (URAER, Ghardaïa) for supporting and financing the solar cooking projects.

\section{NOMENCLATURE}

$\alpha$ Parabolic reflector slope

$\beta^{\prime} \quad$ Parabola azimuth angle

F Focal distance

$f \quad$ Corrected focal distance

$\Omega_{\text {rim }} \quad$ Rim angle

$\mathrm{d}_{\mathrm{v}} \quad$ Diameter of cooking vessel

D Parabola aperture

d Parabola length

$\mathrm{C}_{\max } \quad$ The concentration ratio

$\mathrm{R}_{1}, \mathrm{R}_{2} \quad$ The reflectivity of the glasses

$\mathrm{I}_{\mathrm{s}} \quad$ Incident solar radiation

$\sigma_{\mathrm{s}} \quad$ The Stefan-Boltzmann constant $\left(5.67 \times 10^{-8} \mathrm{~W} / \mathrm{m}^{2} \mathrm{~K}^{4}\right)$

$\mathrm{T} \quad$ The temperature of focal point

\section{REFERENCES}

[1] Hager, T. J., \& Morawicki, R. (2013). Energy consumption during cooking in the residential sector of developed nations: A review. Food Policy, 40, 54-63.

[2] Toonen, H. M. (2009). Adapting to an innovation: Solar cooking in the urban households of Ouagadougou (Burkina Faso). Physics and Chemistry of the Earth, 34(1-2), 65-71.

[3] Stambouli, A. B. (2011). Promotion of renewable energies in Algeria: Strategies and perspectives. Renewable and Sustainable Energy Reviews, 15(2), 1169-1181.

[4] Purohit, I. (2010). Testing of solar cookers and evaluation of instrumentation error. Renewable Energy, 35(9), 2053-2064.

[5] Mullick, S. C., Kandpal, T. C., \& Saxena, A. K. (1987). Thermal test procedure for box-type solar cookers. Solar Energy, 39(4), 353-360.

[6] Funk, P. A. (2000). Evaluating the international standard procedure for testing solar cookers and reporting performance. Solar Energy, 68(1), 1-7.

[7] Funk, P. A., \& Larson, D. L. (1998). Parametric model of solar cooker performance. Solar Energy, 62(1), 6368.

[8] Kerme, E. D., \& Orfi, J. (2015). Exergy-Based Thermodynamic Aalysis of Solar Driven Organic Rankine Cycle. Journal of Thermal Engineering, 1(1), 192-202.

[9] N. Doseva, \& D. Chakyrova. (2014). Energy And Exergy Analyses Of Cogeneration System With A Biogas Engine. In 14th SGEM GeoConference on Energy and Clean Technologies (Vol. 1, p. 173-180 pp).

[10] Dalkiliç, A. S., Çelen, A., Çebi, A., Taner, T., \& Wongwises, S. (2017). Parametric Study Of Energy, Exergy And Thermoeconomic Analyses On A Vapor-Compression System Cascaded With Libr/Water And Nh 3/Water Absorption Cascade Refrigeration Cycles. Anadolu University of Sciences \& Technology-A: Applied Sciences \& Engineering, 18(1).

[11] Xu, C., Wang, Z., Li, X., \& Sun, F. (2011). Energy and exergy analysis of solar power tower plants. In Applied Thermal Engineering (Vol. 31, pp. 3904-3913).

[12] Yettou, F., Azoui, B., Malek, A., Gama, A., \& Panwar, N. L. (2014). Solar cooker realizations in actual use: An overview. Renewable and Sustainable Energy Reviews, 37, 288-306.

[13] Panwar, N. L., Kaushik, S. C., \& Kothari, S. (2011). Role of renewable energy sources in environmental protection: a review. Renewable and Sustainable Energy Reviews, 15(3), 1513-1524.

[14] IEA. World Energy Outlook, ed. Paris: IEA/OECD, 1998.

[15]Nandwani, S. S. (1996). Solar cookers-cheap technology with high ecological benefits. Ecological Economics, 17(2), 73-81.

[16]Hernández-Luna, G., \& Huelsz, G. (2008). A solar oven for intertropical zones: Evaluation of the cooking process. Energy conversion and management, 49(12), 3622-3626.

[17]Nahar, N. M. (1998). Design, development and testing of a novel non-tracking solar cooker. International Journal of Energy Research, 22(13), 1191-1198.

[18]Nahar, N. M. (2000). Solar Cooking-an Appropriate Technology for Development Countries. In World Renewable Energy Congress VI (pp. 2245-2248).

[19]Nahar, N. M. (2009). Design and development of a large size non-tracking solar cooker. Journal of engineering science and technology, 4(3), 264-271. 
[20]Yettou, F., Azoui, B., Malek, A, Gama, A., Panwar, N.L. (2014). Estimation et cartographie des températures d'un cuiseur solaire boîte avec et sans réflecteur en Algérie. Rev. des Energies Renouvelables., SIENR'14 Ghardaïa, 11-18.

[21]Yettou, F., Azoui, B., Malek, A., Panwar, N.L., Gama, A. (2015). Conférence sur le Génie Mécanique, Energétique et Matériaux (CMEME2015), Biskra, Algérie, December 7-10.

[22]Cuce, E., \& Cuce, P. M. (2013). A comprehensive review on solar cookers. Applied Energy, 102, $1399-1421$. [23] Saxena, A., Pandey, S. P., \& Srivastav, G. (2011). A thermodynamic review on solar box type cookers. Renewable and Sustainable Energy Reviews, 15(6), 3301-3318.

[24]Khan, B.H. Non-conventional energy resources, (2008). Tata McGraw Hill Publications: New Delhi, India.

[25]Kothari, D.P., Singal, K.C., Ranjan, R. (2008). Renewable energy resources and emerging technologies, Prentice-Hall: New Delhi, India.

[26]Lahkar, P. J., \& Samdarshi, S. K. (2010). A review of the thermal performance parameters of box type solar cookers and identification of their correlations. Renewable and Sustainable Energy Reviews, 14(6), 1615-1621.

[27] Panwar, N. L., Kaushik, S. C., \& Kothari, S. (2012). State of the art of solar cooking: An overview. Renewable and Sustainable Energy Reviews, 16(6), 3776-3785.

[28]Mirdha, U. S., \& Dhariwal, S. R. (2008). Design optimization of solar cooker. Renewable energy, 33(3), 530544.

[29]Anderson, T.; Duke, M.; Carson, J. (2009). The first international conference on applied energy, Hong Kong, China, January 5-7.

[30]Nahar, N. M., Marshall, R. H., \& Brinkworth, B. J. (1994). Studies on a hot box solar cooker with transparent insulation materials. Energy conversion and Management, 35(9), 787-791.

[31]Mullick, S. C., Kandpal, T. C., \& Kumar, S. (1997). Top heat-loss factor of double-glazed box-type solar cooker from indoor experiments. Energy, 22(6), 559-565.

[32] Srinivasan Rao, K.V.N. (2007). Fifth international energy conversion engineering conference and exhibit, St. Louis, Missouri, USA, June 25-27.

[33]Mahavar, S., Sengar, N., Rajawat, P., Verma, M., \& Dashora, P. (2012). Design development and performance studies of a novel single family solar cooker. Renewable energy, 47, 67-76.

[34]Mahavar, S., Rajawat, P., Marwal, V. K., Punia, R. C., \& Dashora, P. (2013). Modeling and on-field testing of a Solar Rice Cooker. Energy, 49, 404-412.

[35]Kumar, N., Agravat, S., Chavda, T., \& Mistry, H. N. (2008). Design and development of efficient multipurpose domestic solar cookers/dryers. Renewable Energy, 33(10), 2207-2211.

[36]Kumar, N., Chavda, T., \& Mistry, H. N. (2010). A truncated pyramid non-tracking type multipurpose domestic solar cooker/hot water system. Applied Energy, 87(2), 471-477.

[37]Farooqui, S. Z. (2015). An improved power free tracking system for box type solar cookers. Solar Energy, $120,100-103$.

[38]Yettou Gama, F. ., Azoui, B. ., Malek, A. ., Panwar, N. L. ., \& Gama, A. . (2015). Energetic and exergetic evaluation of solar box cooker in Algerian climatic conditions. International Journal of Exergy, 16(3), 337-357.

[39]Gama, A., Larbes, C., Malek, A., Yettou, F., \& Adouane, B. (2013). Design and realization of a novel sun tracking system with absorber displacement for parabolic trough collectors. Journal of Renewable and Sustainable Energy, 5(3).

[40]Arenas, J. M. (2007). Design, development and testing of a portable parabolic solar kitchen. Renewable Energy, 32(2), 257-266.

[41]Sharaf, E. (2002). A new design for an economical, highly efficient, conical solar cooker. Renewable Energy, 27(4), 599-619.

[42]Sonune, A. V., \& Philip, S. K. (2003). Development of a domestic concentrating cooker. Renewable Energy, 28(8), 1225-1234.

[43]Al-Soud, M. S., Abdallah, E., Akayleh, A., Abdallah, S., \& Hrayshat, E. S. (2010). A parabolic solar cooker with automatic two axes sun tracking system. Applied Energy, 87(2), 463-470..

[44]Abu-Malouh, R., Abdallah, S., \& Muslih, I. M. (2011). Design, construction and operation of spherical solar cooker with automatic sun tracking system. Energy Conversion and Management, 52(1), 615-620.

[45]Valmiki, M. M., Li, P., Heyer, J., Morgan, M., Albinali, A., Alhamidi, K., \& Wagoner, J. (2011). A novel application of a Fresnel lens for a solar stove and solar heating. Renewable Energy, 36(5), 1614-1620.

[46]Sosa-Montemayor, F., Jaramillo, O. A., \& Del Rio, J. A. (2009). Thermodynamic analysis of a solar coffee maker. Energy Conversion and Management, 50(9), 2407-2412.

[47]Gallagher, A. (2011). A solar fryer. Solar energy, 85(3), 496-505.

[48] Badran, A. A., Yousef, I. A., Joudeh, N. K., Al Hamad, R., Halawa, H., \& Hassouneh, H. K. (2010). Portable solar cooker and water heater. Energy Conversion and Management, 51(8), 1605-1609.

[49] Lecuona, A., Nogueira, J. I., Ventas, R., \& Legrand, M. (2013). Solar cooker of the portable parabolic type incorporating heat storage based on PCM. Applied energy, 111, 1136-1146..

[50] Esen, M. (2004). Thermal performance of a solar cooker integrated vacuum-tube collector with heat pipes 
containing different refrigerants. Solar Energy, 76(6), 751-757.

[51] Hussein, H. M. S., El-Ghetany, H. H., \& Nada, S. A. (2008). Experimental investigation of novel indirect solar cooker with indoor PCM thermal storage and cooking unit. Energy conversion and management, 49(8), 2237 2246.

[52] Yettou, F., Azoui, B., \& Malek, A. (2013, May). Determination of adjustment tracking time in two types of solar cookers by ray-tracing method. In Power Engineering, Energy and Electrical Drives (POWERENG), 2013 Fourth International Conference on (pp. 822-827).

[53] Matlab/Simulink Tutorial, (2000). School of Electrical, Electronic and Computer Engineering, Version 7.10, $1^{\text {st }}$ Edition.

[54] Yettou, F., Malek, A., Haddadi, M., \& Gama, A. (2009). Etude comparative de deux modèles de calcul du rayonnement solaire par ciel clair en Algérie. Revue des Energies Renouvelables, 12(2), 331-346.

[55] SolidWorks, SolidWorks Corporation, 300 Baker Avenue, Concord, MA 01742. Available from: http://www.solidworks.com/.

[56] Lambda Research Corporation, USA, (2000). TracePro software for opto-mechanical modeling user manual release 6 revision 03 , p. 2.7-2.13.

[57] Chong, K. K., Lim, C. Y., \& Hiew, C. W. (2011). Cost-effective solar furnace system using fixed geometry Non-Imaging Focusing Heliostat and secondary parabolic concentrator. Renewable Energy, 36(5), 1595-1602.

[58] Surfer User's guide, (1999). $3^{\mathrm{ème}}$ edition, Golden Software Inc.

[59] Hofierka, J.; Suri, M.; Súri, M. In: Proc. Open source GIS-GRASS users Conf (2002). Trento, Italy, September 11-13.

[60] Gschwind, B., Ménard, L., Albuisson, M., \& Wald, L. (2006). Converting a successful research project into a sustainable service: the case of the SoDa Web service. Environmental Modelling \& Software, 21(11), 1555-1561. [61] Gama, A., Yettou, F., Malek, A., Larbes, C., Azoui, B. (2010). In: $2^{\text {nd }}$ International Conference on Nuclear and Renewable Energy Resources (NURER10), Ankara, Turkey.

[62] Capderou, M. (1987). Atlas Solaire de l'Algérie, Aspect Géométrique, Synthèse Géographique, Vol.1, T3, Office des Publications Universitaires, EPAU: Algérie. 